\title{
Degradation of Micro- and Nano-Plastics by Photocatalytic Methods
}

\author{
Bratovcic A* \\ Department of Physical Chemistry and Electrochemistry, Faculty of Technology, University of Tuzla, Bosnia and Herzegovina
}

*Corresponding author: Bratovcic A, Department of Physical Chemistry and Electrochemistry, Faculty of Technology, University of Tuzla, Univerzitetska 8, 75000 Tuzla, Bosnia and Herzegovina, E-mail: amra.bratovcic@untz.ba

Citation: Bratovcic A (2019) Degradation of Micro- and Nano-Plastics by Photocatalytic Methods. J Nanosci Nanotechnol Appl 3: 304

Article history: Received: 02 October 2019, Accepted: 01 November 2019, Published: 04 November 2019

\begin{abstract}
In the last couple of years, an increasing number of dead marine animals that are full of plastic waste which ends up in the seas and oceans has been evident. Actually, micro-plastics $(5-1000 \mu \mathrm{m})$ have been detected in the stomachs of commercially important fish from the Mediterranean, as well as some drinking water in plastic bottles. Today, humanity is struggling with the presence of micro- and nanoplastics in enormous quantities in the oceans, seas, rivers and lakes. World plastic production almost reached 350 million tonnes in 2017, where China is the largest producer of plastics, $29.4 \%$ followed by Europe with $18.5 \%$.

There is experimental evidence that three weeks of UV irradiation generates plastics particles in the nanometer size range. Nanoparticles (1-100 nm) usually exhibit different chemical and physical properties than macroscopic objects based on the same material. At the micro- and nanoscales, polyvinyl chloride (PVC), polyethylene terephthalate (PET), polystyrene (PS) and polyethylene (PE) were observed. Recent study has shown that carbon-based molecules could break down marine microplastics without harming surrounding microorganisms. Successful degradation of low-density polyethylene film (LDPE) in water by using visible light excited heterogeneous zinc oxide photocatalysts was achieved, as well as polyethylene (PE) plastic with polypyrrole/ $/ \mathrm{TiO}_{2}\left(\mathrm{PPy} / \mathrm{TiO}_{2}\right)$ nanocomposite as photocatalyst. Our current knowledge about nanoplastics in the environment is still very limited and only a few scientific publications are available. For this reason, micro- and nanoplastics are considered as an emerging issue of great concern. Photocatalytic degradation of plastics leads to the formation of lower molecular weight intermediates that can be further used as a raw materials for the chemical industry for the production of new petrochemical products or plastics or in organic synthesis. This review provides an overview of the latest catalytic and photocatalytic methods of degradation of microplastics, as well the quantities of global plastic produced in the world and their impact on human health.
\end{abstract}

Keywords: Micro-plastics; Nano-plastics; Degradation; Photocatalytic Methods

\section{Introduction}

Synthetic plastic production is one of the fastest growing fields of global industry. Plastics are synthetic organic polymers considered as ideal materials with an extensive variety of applications by many industries like the manufacturing industry which uses a million tons of plastic per year to produce textile fibres, while the food industries use plastic for packaging products, enabling the reduction of food wastage and transportation costs. Currently, there are over 30000 different natural and synthetic polymers. Knowing the species and potentially harmful impact on human health is imperative in selecting and using certain types of polymers [1]. Plastics can be fossil-based or bio-based and in both cases they can also be bio-degradable. Plastics have been found worldwide in the marine environment over 250000 tons afloat at sea [2].

A long-chain polymer structure with a high molecular weight $\left(M_{w}\right)$, hydrophobicity, and crystallinity are crucial characteristics responsible for plastics' resistance to biodegradation [3]. Large compounds with a high Mw cannot be transported across the cellular membrane of microorganisms. Thus, long-chain polymers have to be first depolymerized to smaller monomers before they can cross the cell membrane [4]. Next, monomers can pass through the cell membrane, followed by assimilation by intracellular metabolism [5].

Due to the fact that most petrochemical plastics are not biodegradable, new biodegradable plastics (BPs) have been developed and some of them have already been introduced to the market. Nowadays, there are many products available (bottles, packages) that are made from biodegradable plastics such as poly(lactic acid) (PLA), poly(e-caprolactone) (PCL), poly(butylene succinate) (PBS), or poly(butylene succinate-co-butylene adipate) (PBSA) [6]. In a recently published review paper (2019) [7] micro- and nanoplastic 
contaminations in food and in edible animal species since 2010 were critically analysed. In total, they collected data regarding the microplastic contamination of 201 edible animal species (164 sea fish, 23 molluscs, 7 crustaceans, 2 birds, 2 sweet water fish, 2 turtles, chicken), some food products (canned sardines and sprats, sea salt, sugar and honey), as well as beer and water.

Today better understanding of the mechanisms by which plastics are transported through the rivers to the oceans, their change and potential decay along these pathways and their accumulation in rivers, sediments, soils and organisms, as well as the effects of such plastics on the affected ecosystems, including organisms at all levels of the food chain is urgently needed. Plastic wastes might be dangerous for the natural environment due to accumulation in the rivers and oceans. Plastic waste present into oceans and rivers poses a global environmental threat with damaging health consequences for animals, humans and ecosystems. There is a concern that plastic is a source of toxic chemicals such as polychlorinated biphenyls or phthalates and bisphenol A [8]. These contaminants have also a significant influence on marine fauna due to entanglement, suffocation and disruption of digestion in birds, fish, mammals and turtles [9]. After being discharged into the environment, plastics are subject to physical, chemical and biological weathering and break down into microplastics [10] ( $<5 \mathrm{~mm}$ in diameter) and eventually into nanoplastics [11] $(<1 \mu \mathrm{m}$ in at least one of their dimensions).

Low density plastics such as polystyrene (PS) or polyethylene (PE) floating at the surface of the river which exposed to sun light may cause chemical and physical changes that bypass those higher density plastics that are suspended in the river or even have found their way into the sediment at the river bed. Further, sediment-bound plastics may take years or even decades to make their way into the oceans, by which time their interactions with biological materials including different types of microbial biofilms may change their properties and behaviour, contaminants may have absorbed on their surfaces and they may have cause long-term exposures to vulnerable organisms [12].

In Figure 1 is shown the way of gradual degradation of macroplastics to micro- and nanoplastics, their interaction with the medium and health impact on human body leading to different diseases.

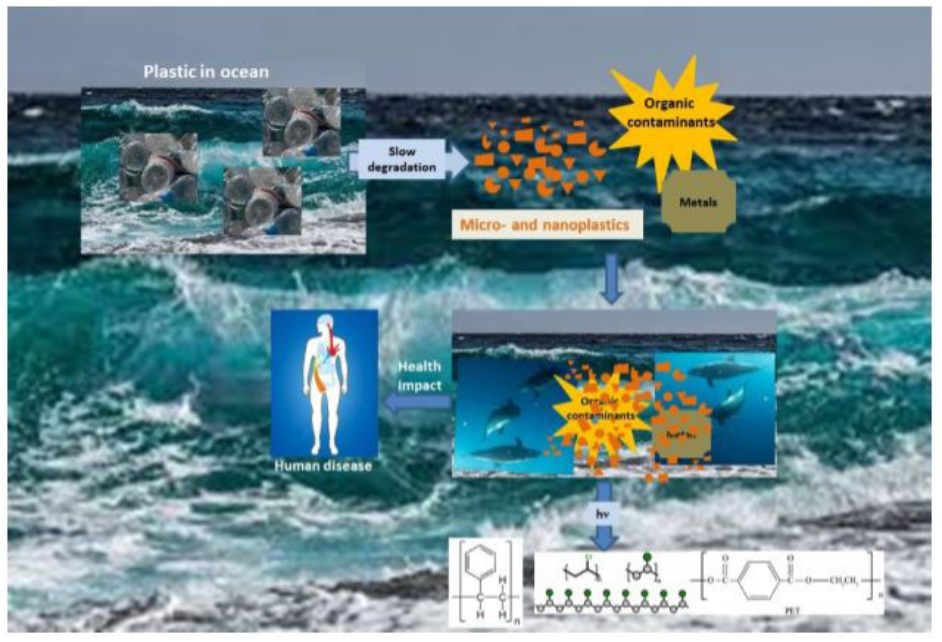

Figure 1: Schematic illustration of the degradation of plastics to

micro- and nano-plastics and their impact on human health

Microplastics (MPs) are defined as insoluble particles less than five millimetres in size many invisible to the eye [13]. MPs have trigger increasing concern as they pose threats to aquatic species as well as human beings. They do not only contribute to accumulation of plastics in the environment, but due to absorption they can also contribute to spreading of micropollutants in the environment [14]. MPs adsorb organic and metal contaminants as they travel through water and release these hazardous substances into aquatic organisms when eaten, causing them to accumulate all the way up the food chain. Natural decomposition of MPs can take up to decades and will release a diversity of hazardous organic substances from the polymers and additives such as plasticizer and antioxidizer in manufacturing [15]. The sources of microplastics are manifold, including wastewater inputs, runoff from roads and sealed surfaces or inappropriate waste management. While wastewater treatment can reduce the amount of plastics, a large number of particles continue to end up in rivers around the world. Further, biosolids as residuals of wastewater treatment processes may be used in agriculture as fertilizers, meaning that microplastics can find their way into soils and potentially valuable groundwater resources via other pathways that are not yet well understood.

A subfraction of microplastics with sizes equal to or less than $100 \mathrm{~nm}$ in at least one dimension are described as nanoplastics. Nanoparticles usually exhibit different chemical and physical properties than macroscopic objects based on the same material [16]. Therefore, the superficial area of nanoparticles and other physicochemical properties may greatly influence their transformation and bioavailability during spreading into environment [17]. Thus, the differences between micro- and nanoplastics are not trivial and the interactions of nanoplastics with the environment and organisms are a specific concern [18]. A clear understanding of the interaction of nanoplastics with the environment, especially with living organisms, is important to assess possible health hazards, especially because nanoplastic particles can react differently than their micron sized counterparts. 
Polyethylene terephthalate (PET), low-density polyethylene (LDPE), high-density polyethylene (HDPE), polyvinyl chloride (PVC), polypropylene (PP) and polystyrene (PS) are the most widespread and studied plastic materials. Other plastics include acrylic, nylon, polycarbonate, polyurethanes, polylactic acid, and other biodegradable plastics.

However, nanoplastics have recently been collected in the North Atlantic [19], while styrene monomers and oligomers have been found in sand and water from shorelines worldwide. They reveal that the fingerprint of the colloidal fraction of seawater was anthropogenic and attributed to a combination of plastics. The polymer composition varied among the size classes. At the micro- and nanoscales, polyvinyl chloride (PVC), polyethylene terephthalate (PET), polystyrene (PS) and polyethylene (PE) were observed. They also observed changes in the pyrolytic signals of polyethylene with decreasing debris size, which could be related to the structural modification of this plastic as a consequence of weathering.

Lambert and Wagner have shown in a controlled experiment that three weeks of UV radiation generates plastics particles in the nanometer size range [20]. Increased reliance on plastic, which degrades extremely slowly in the environment, is resulting in increased accumulation of micro- or nanoplastics in fresh and marine waters, whose eco-toxicological impacts are as yet poorly understood.

Nasser and Lynch, (2016) [21] used carboxylic acid and amino modified spherical polystyrene nanoparticles (NPs), to assess interaction of NPs with biomolecules secreted by Daphnia magna and the impact of these interactions on NP uptake, retention and toxicity towards Daphnia magna. Daphnia magna are an important environmental indicator species who may be especially sensitive to NPs as a result of being filter-feeders. The research carried out by Professor Lynch demonstrated that daphnia release proteins that attach in a process known as adsorption, forming an eco-corona around the nanoplastic particles that changes how organisms interact with the nanoplastics.

\section{Behaviour of micro- and nanoplastics}

Microplastics can be up taken by ingestion and after absorption may enter into different tissues and cells potentially resulting in several types of adverse effects [22-27]. Research carried out by Barboza and Gimenez, (2015) [28] has shown that shellfish and several types of commercially important fish are often contaminated with microplastics being a potential route through which human consumers become exposed to MPs [29].

In European countries with high shellfish consumption, consumers ingest up to 11000 microplastic particles (size range 5-1000 $\mu \mathrm{m})$ per year, whereas in countries with low shellfish consumption, consumers ingest an average of 1800 microplastics per year [30] which is still a considerable exposure. If one consider only shrimp consumption, research indicate about 175 microplastic particles (size range $200-1000 \mu \mathrm{m}$ ) per person per year [31]. Regarding mussels consumption by humans, microplastics were found in Mytilus edulis and M. galloprovincialis from France, Italy, Denmark, Spain and The Netherlands [32].

Moreover, microplastics have been detected in the stomachs of commercially important fish from the Mediterranean [33] and in the gastrointestinal tract and liver of anchovies and sardines that are sometimes entirely consumed [34,35]. Generally seafood species that we eat whole such as molluscs and crustaceans and small or juvenile phases of fish pose a greater threat to seafood contamination than for example gutted fish or peeled shrimp. Moreover, some drinking water in plastic bottles, glass bottles and beverage cartons commercially available from German stores were also found to contain microplastics [36] as well as tap water from different countries [37].

The main subject of this review is to describe the polymers degradation by photocatalytic methods, their advantages and disadvantages compared to other methods.

\section{Methods of degradation}

Plastic recycling can be divided into four categories: primary, secondary, tertiary and quaternary.

Primary involves the re-extrusion, that is, the return of plastics of the same characteristics to the production process itself. Secondary involves mechanical recycling, i.e. the recycling of various different plastic products by physical processes. Tertiary involves chemical recycling with the aim of producing raw materials for the chemical industry. Quaternary means the production of energy, that is, the complete or partial oxidation of plastic waste materials for the purpose of producing heat, and/or gaseous fuels, oils, and/or material being disposed of.

Particular attention will be paid to tertiary, i.e. chemical recycling, which decomposes plastics into polymers of smaller molecular weights (usually liquids or gases), which may be used as raw materials for the production of new petrochemical products or plastics. In these processes, the change necessarily occurs in the chemical structure of the polymer. In recent years, much attention has been paid to this recycling approach such as non-catalytic cracking, thermal catalytic cracking and steam degradation in order to produce different types of fuel from plastic waste. Polyethylene terephthalate (PET), certain polyamides (nylon 6 and 6,6), and polyurethanes can be effectively depolymerized. The resulting chemicals can then be used to produce new plastic that is not significantly different from the original intact polymer. Chemical recycling is, in fact, a major advantage with the ability to treat heterogeneous and contaminated polymers with limited use of pretreatment. Chemical recycling aims at the fabrication of valued products, such as 
monomers or petrochemical feedstocks, particularly from mixed PE/PP/PS, multilayer packaging, fibre-reinforced composites, or PU [38]. Existing expertise largely relies on access to pure waste polymer feedstocks, which necessitate sorting of waste that is costly and time-intensive. Thermolysis makes available lower-molecular-weight products throughout a recycling strategy that decomposes polymers [39] monomers from depolymerisation need selective and effective catalysts that meet cost and energy metrics [40].

\section{Thermal and mechanical degradation}

Aboulkas, et al. (2010) [41] have studied the thermal degradation behaviours of polyethylene (PE) and polypropylene (PP), high density polyethylene (HDPE), low density polyethylene (LDPE) at different heating rates (2, 10, 20 and $50 \mathrm{~K} / \mathrm{min})$ from TG/DTG curves. The weight loss curves indicated that HDPE, LDPE and PP have the same pyrolysis behaviours due to similar chemical bonds in their molecular structures. The weight losses show that degradation of plastic occurs almost totally in a one-step process as can be concluded by the presence of only one peak in DTG. The plastic thermal degradation starts at $577 \mathrm{~K}$ and is almost complete at approximately $850 \mathrm{~K}$.

Ekvall, et al. (2019) [42] studied the products formed by the mechanical breakdown of two commonly used polystyrene products (PS), takeaway coffee cup lids and expanded polystyrene (EPS) foam. They found that daily-use polystyrene products can break down into nanoparticles with spherical and elongated shapes with negative or nearly neutral surface charges. It was shown previously that polystyrene (PS) particles with different sizes and surface modifications have different negative effects on wildlife. This indicates that broken down nanoparticles might have the potential to cause cocktail effects in nature.

\section{Biodegradation}

Romera-Castillo, et al. (2018) [43] have shown that in seawater, plastic releases dissolved organic carbon, stimulating the activity of heterotrophic microbes being used for biodegradation, species belonging to Pseudomonas, Streptomyces, Corynebacterium, Arthrobacter, Micrococcus, and Rhodococcus are mentioned most often [44]. Moreover, 12 of the isolated strains were able to produce lipase [45], an enzyme that hydrolyses ester bonds in lipids and in some polyesters.

The collaborative study, led by Shaobin Wang and Xiaoguang Duan have developed tiny spring-shaped carbon-based molecules that could break down marine microplastics without harming surrounding microorganisms [46]. They presented integrated carbocatalytic oxidation and hydrothermal (HT) hydrolysis of microplastics over magnetic spring-like carbon nanotubes. The robust carbon hybrids exhibited an outstanding MPs degradation performance by catalytic activation of peroxymonosulfate to generate reactive radicals. The toxicity tests indicated that the organic intermediates from MPs degradation were environmentally benign to the aquatic microorganisms and can serve as a carbon source for algae cultivation. They provided a green strategy by integrating state-of-the-art carbocatalysis and nanotechnology for remediation of MPs contamination in water.

\section{Photocatalytic degradation of microplastics}

Actual remediation methods include filtration and incineration, but those methods require high energy or generate unwanted byproducts. Apart from the methods mentioned above, bacterial, catalytic and advanced oxidation processes (AOPs) such as ozonation and photocatalytic methods for degradation of MPs will be discussed here.

So far, known studies concerning photocatalytic degradation of plastics lead to the formation of lower molecular weight intermediates that can be further used in organic synthesis. There is still little research of the use of photocatalytic methods for plastic degradation, but the advantages are certainly in the use of solar radiation and photocatalysts to convert waste into more useful intermediate products that can be further used in the synthesis of new products. Therefore, the development of photocatalytic process using renewable energy sources such as solar energy is an increasingly attractive option from the economic, energetic and environmental perspective.

Advanced oxidation processes, which are characterized by the generation of in-situ reactive species, primarily hydroxyl radicals $(\cdot \mathrm{OH})$, have been recognized as one of the potential technologies for degradation of plastic waste. Ozonation, a combination of ozone and UV radiation, a combination of peroxide $\left(\mathrm{H}_{2} \mathrm{O}_{2}\right)$ and UV radiation, as well as a combination of UV radiation and photocatalysts are the most studied AOPs. The major drawback of all AOPs is the high maintenance costs, which somewhat limits the widespread practical application of these extremely powerful technologies. With the appearance of highly efficient sources of UV radiation, catalysts that absorb radiation from the visible spectrum, and the improvement of the reactor design itself, technologies based on the application of UV and solar radiation have great potential for widespread use. However, further research is necessary to make this possible.

Total mineralization of organic pollutants is generally not economically viable and is not always necessary. Partial oxidation of the starting compound to less stable intermediates is a possible alternative, especially if the resulting intermediates are susceptible to further degradation in the environment and do not pose a risk to aquatic environment and human health. However, partial oxidation of organic pollutants may in certain cases lead to the formation of intermediates that are more toxic than the starting compound, and the nature and number of degradation products depend on the oxidation process applied, the treatment time and the quality of the aqueous matrix. 
Tofa and co-workers (2019) [47] showed successful degradation of microplastic fragments, low-density polyethylene (LDPE) film of size $(1 \mathrm{~cm} \times 1 \mathrm{~cm})$ in water using visible light excited heterogeneous zinc oxide photocatalysts. In Figure 2 photocatalytic equipment is present.

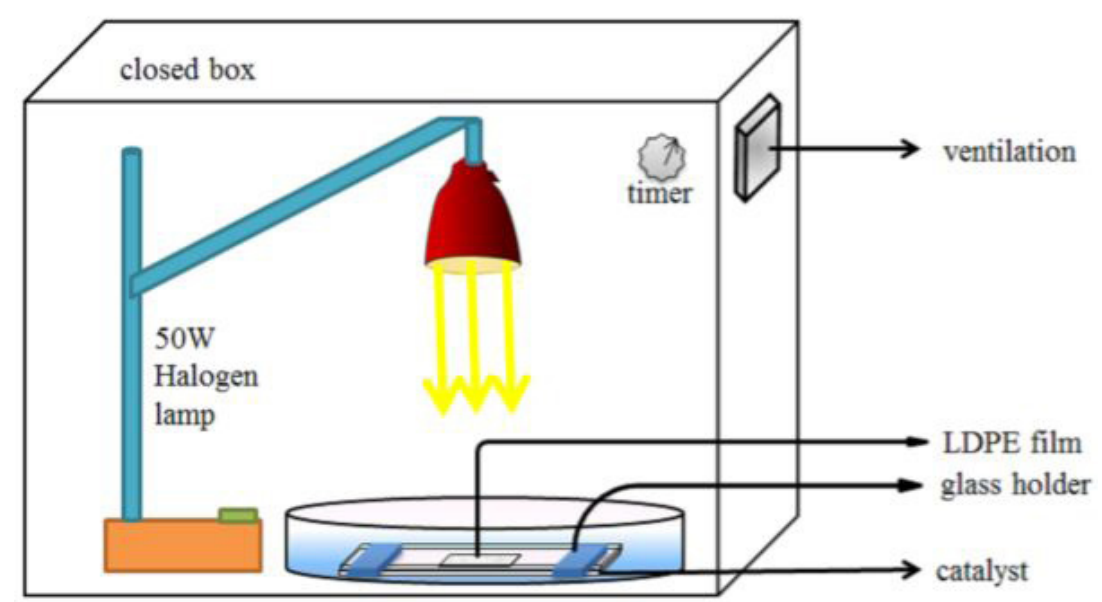

Figure 2: Equipment for the photocatalytic experiment [47]

Photocatalytic LDPE oxidation led to the formation of low molecular weight compounds like hydroperoxides, peroxides, carbonyl and unsaturated groups. Furthermore, the results of their study showed that degree of oxidation of LDPE was directly proportional to the catalyst surface area [47].

Shengying Li and co-workers (2010) carried out the degradation of polyethylene (PE) plastic under sunlight irradiation with polypyrrole/ $\mathrm{TiO}_{2}\left(\mathrm{PPy} / \mathrm{TiO}_{2}\right)$ nanocomposite as photocatalyst, which were prepared by sol-gel and emulsion polymerization methods. They found that irradiating the PE plastic for 240 hours by sunlight reduced its weight up to $35.4 \%$ and $54.4 \%$ of $M_{w}$, respectively. According to this study, the AFM images showed the formation of cavities on PE plastic surface. FTIR spectroscopic studies indicated that a strong interaction existed between the interface of $\mathrm{PE}$ and $\mathrm{PPy} / \mathrm{TiO}_{2}$ and caused the degradation of $\mathrm{PE}$ [48].

Tian et al. (2019) [49] studied degradation and mineralization of polystyrene (PS) nanoplastics under ultraviolet (UV) radiation at $254 \mathrm{~nm}$ using ${ }^{14} \mathrm{C}$ radioisotope tracer technology. ${ }^{14} \mathrm{C}$-polystyrene (PS) nanoplastics were synthesized from ${ }^{14} \mathrm{C}$-styrene. In order to study the role of water during the photodegradation of PS nanoplastics, 14C-PS nanoplastics were exposed to UV radiation in air or suspended in water. The X-ray photoelectron spectroscopy (XPS) results showed that after 48 hours of UV irradiation, C-O groups formed on the surface, while no significant change was observed from the Fourier-transform infrared spectroscopy (FTIR) analysis, indicating that short-term photo-oxidation only occurs on the thin surface layer of the PS nanoplastics. The molecular weight $\left(M_{w}\right)$ of the PS nanoplastics increased in air after the irradiation, suggesting cross-linking of the PS chains, while it did not show significant changes in the presence of water. The mineralization of the PS nanoplastics was higher in water $(17.1 \pm 0.55 \%)$ than in air $(6.17 \pm 0.1 \%)$. A significant amount $(11.0 \pm 0.1 \%)$ of by-products with small $M_{w}$ was detected in water during UV irradiation, much higher than that being washed out from the surface of nanoplastics exposed in air. The higher photoreactivity in water suggests that the mechanisms underlying the phototransformation of the PS nanoplastics in the two matrices could be different. The present study provided the first evidence of photodegradation of PS nanoplastics in aqueous environments.

In the study of Ariza-Tarazona et al. (2018) [50], they proposed the use of the sustainable photocatalytic process to degrade PE microplastics as a promising alternative to minimize its introduction rate to the oceans from continental sources. The photocatalytic degradation of real samples of HDPE microplastics extracted from a commercially available facial scrub, one of the products that have been suggested as a significant source of marine microplastics was conducted by using $\mathrm{N}_{-}-\mathrm{TiO}_{2}$ which was exposed to visible light. The photocatalytic experiments performed with the mussel-derived $\mathrm{N}-\mathrm{TiO}_{2}$ powders were carried using microplastics/ $\mathrm{N}$ $\mathrm{TiO}_{2}$ film composites. In this research, more sustainable $\mathrm{N}-\mathrm{TiO}_{2}$, derived from the extrapallial fluid of saltwater mussels, presented an excellent capacity to promote mass loss of HDPE microplastics in the solid and aqueous environment. The other photocatalyst, derived from a conventional less sustainable sol-gel route, also presented good capacity to promote mass loss of the as-extracted microplastics in an aqueous environment. Results showed that the environmental conditions (those that promote water adsorption into the $\mathrm{N}-\mathrm{TiO}_{2}$ ), the pollutant $/ \mathrm{N}-\mathrm{TiO}_{2}$ interaction and the photocatalyst surface area should be carefully set or designed in order of avoiding the arrest of photocatalysis. Mass losses, SEM and FTIR analysis confirmed HDPE degradation. UV rays have a strong photochemical and photobiological effect.

KTH Royal Institute of Technology in Sweden has developed a method which uses a filter coated with nano-sized semiconductors that initiate and speed up a natural process called photocatalytic oxidation. Photocatalyst activates the breakup of compounds by exciting electrons causing water molecules to break down into their constituent parts: hydrogen and oxygen. Solar radiation captured by the filter is then used to create a reaction where by the radicals exchange electrons with the atoms that make up the microplastics - effectively pulling them apart into harmless $\mathrm{CO}_{2}$ and water [51]. 


\section{Plastic production today}

The world's plastic production almost reached 350 million tonnes in 2017 including thermoplastics, polyurethanes, thermosets, elastomers, adhesives, coatings and sealants and (polypropylene) PP-fibers, and not including (polyethylene terephthalate) PET-, (polyamide) PA- and polyacryl-fibers. China is the largest producer of plastics, $29.4 \%$, followed by Europe, $18.5 \%$ and NAFTA, $17.7 \%$ (Figure 3).

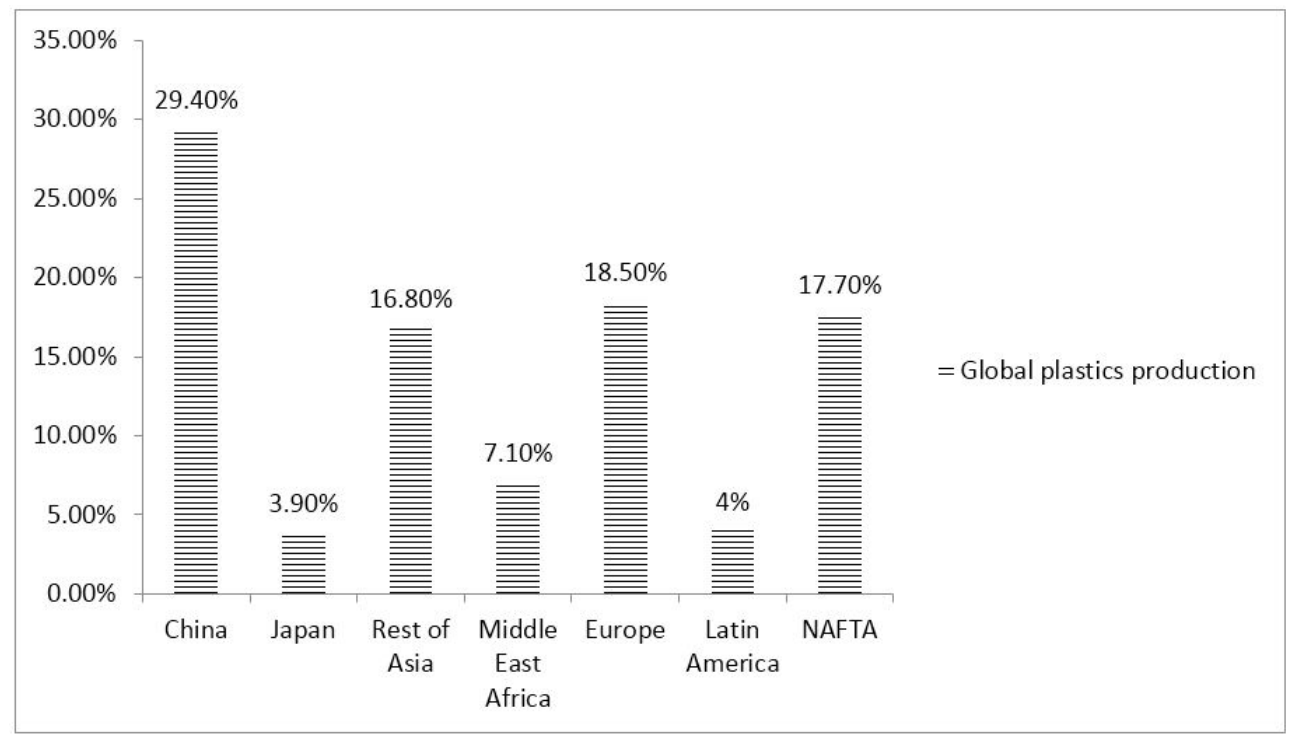

Figure 3: Distribution of global plastics production

The plastic industry gives direct employment to more than 1.5 million people in Europe in which close to 60000 companies operate. The European plastic industry had a turnover of 355 billion euros in 2017. In 2016, over 8.4 million tonnes of plastic waste were collected in order to be recycled inside and outside the EU [52].

\section{Life cycle of Plastic}

In order to understand the life cycle of plastic products it is important to understand that not all plastic products are the same and not all have the same service life. Plastic become waste at the end of their service life. In ten years, from 2006 to 2016 , plastic waste recycling has increased by $79 \%$, energy recovery increased by $61 \%$, and landfill decreased by $43 \%$. In $2016,27.1$ million tonnes of plastic waste were collected in the EU and for the first time, more plastic waste was recycled than landfilled. In Figure 4 is shown that from 27.1 million tonnes of plastic waste $41.6 \%$ was used for energy recovery, $31.1 \%$ was recycled and that (63\% inside the EU and $37 \%$ outside EU) and $27.3 \%$ landfill.

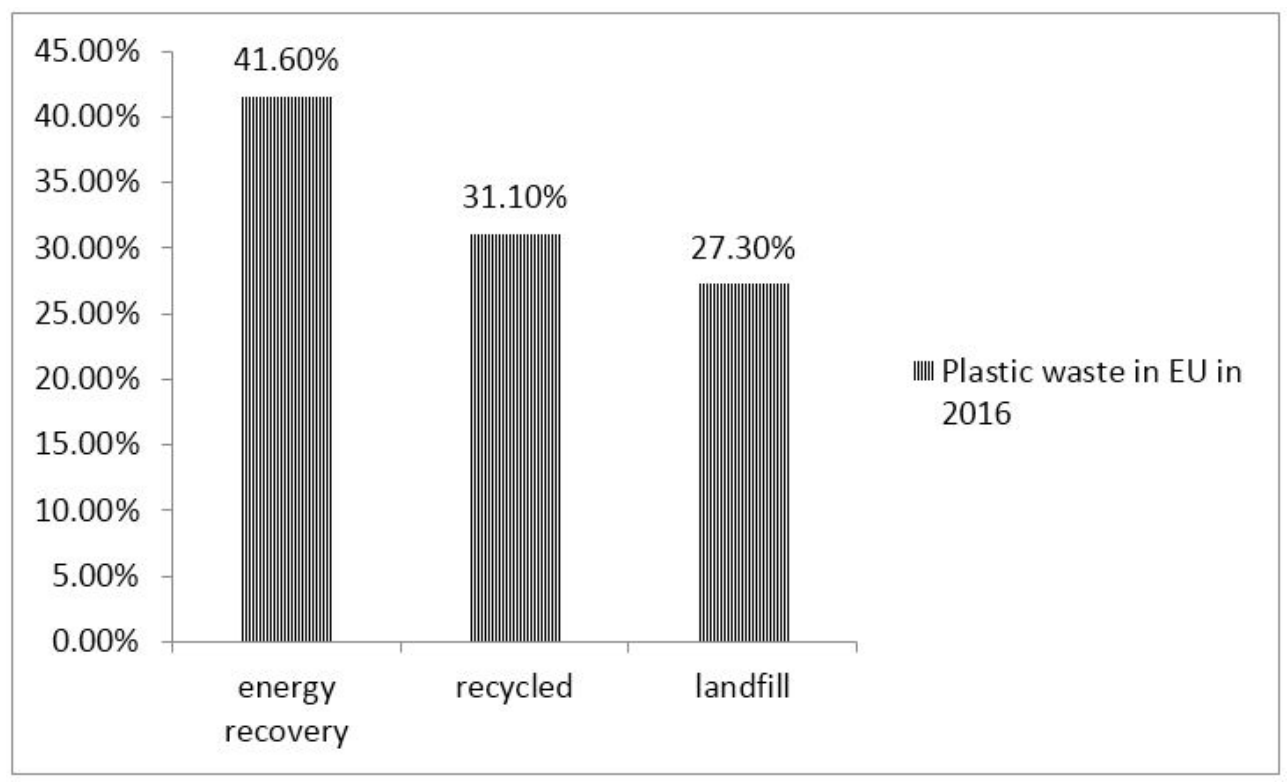

Figure 4: Plastic waste in EU in 2016

Recycling is the first option for plastic packaging waste. In 2016, 19 countries had plastic packaging recycling rates higher than $35 \%$. Germany and Czech Republic are two countries which achieved a recycling rate of 50\% or more. In Germany, in $2016,5.1$ 
million tonnes of plastic post-consumer waste were collected. In Germany, according to data from Plastics Europe shown in Figure 5 , from 2006 to 2016, the volumes for recycling plastic increased by $76 \%$, energy recovery increased by $64 \%$ and landfill decreased by $77 \%[52]$.

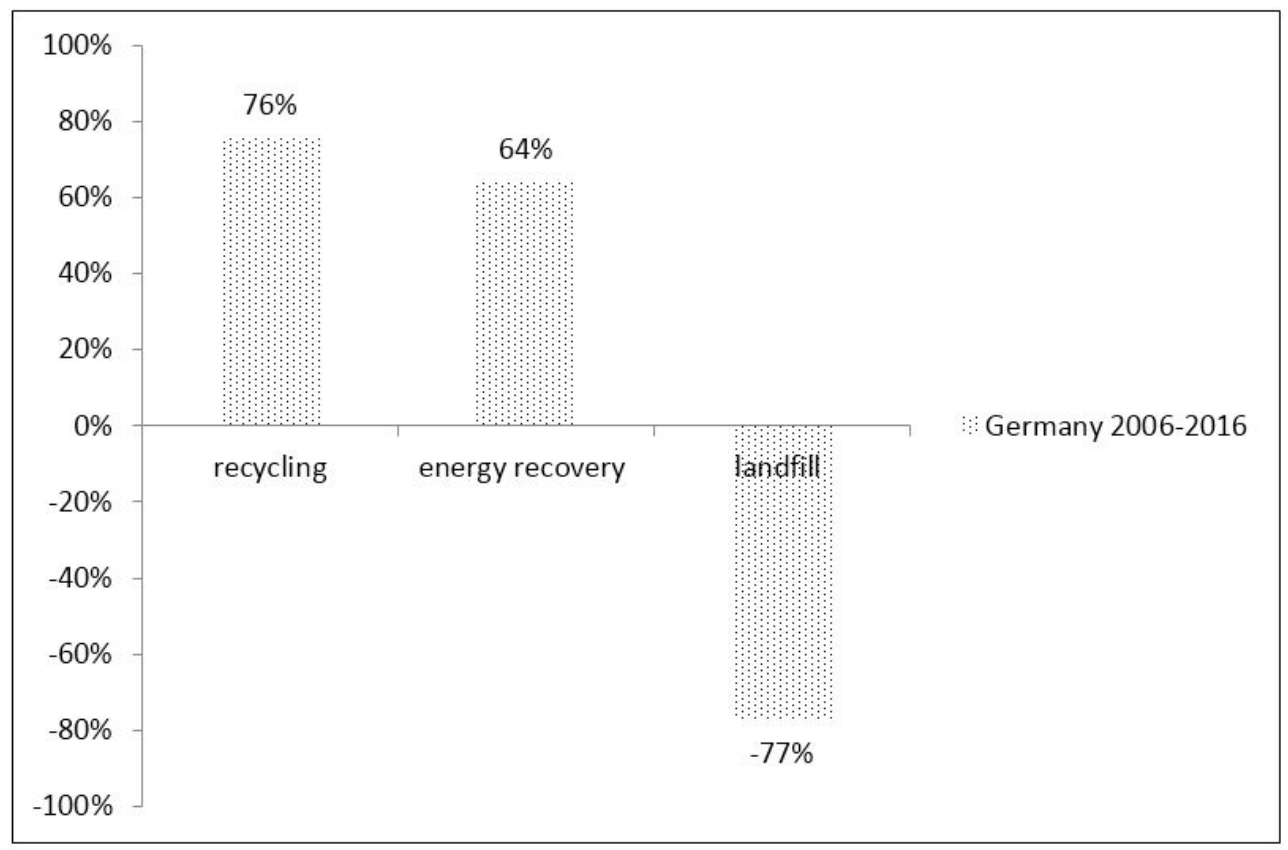

Figure 4: The volumes for recycling plastic in Germany from 2006-2016

\section{Conclusions}

Today, micro- and nanoplastics are ubiquitous in the environment. Their tiny size makes microplastics behave in interesting and consequential ways. As particles reduces in size, the proportion of surface area to volume increases. The chemical behaviour of small particles is then driven more by the properties of their surface area than by their constituent materials. As such, the ways that micro- and nanoplastics interact with the environment cannot be predicted from the behaviour of macroplastics. Therefore, understanding the microplastics contamination routes of foods and beverages is a key element towards the evaluation of the extent of food contamination. It is also important to understand the interaction of nanoplastics with the environment, especially with living organisms, and assess possible health hazards, because nanoplastic particles can react differently than their micron sized counterparts. Preventative microplastic pollution measures should be politically and socioeconomically feasible. The results of this review provide new insights into the use of a sustainable and clean photocatalytic process to degrade micro- and nanoplastics into a useful lower molecular weight of organic species which can be further used in organic synthesis production of new chemical products or plastics. Photocatalytic degradation is a promising alternative to minimize microplastic pollution from continental sources with reduced by-products.

\section{References}

1. Bratovčić A, Odobašić A, Ćatić S, Šestan I (2015) Application of polymer nanocomposite materials in food packaging. Croat J Food Sci Technol 7: 86-94.

2. Eriksen M, Lebreton LCM, Carson HS, Thiel M, Moore CJ, et al. (2014) Plastic pollution in the world's oceans: more than 5 trillion plastic pieces weighing over 250,000 tons afloat at sea. PLoS One 9: e111913.

3. Wilkes RA, Aristilde L (2017) Degradation and metabolism of synthetic plastics and associated products by Pseudomonas sp.: capabilities and challenges. J Appl Microbiol 123: 582-93.

4. Shah AA, Hasan F, Hameed A, Ahmed S (2008) Biological degradation of plastics: a comprehensive review. Biotechnol Adv 26: $246-65$.

5. Kolvenbach BA, Helbling DE, Kohler HP, Corvini PF (2014) Emerging chemicals and the evolution of biodegradation capacities and pathways in bacteria. Curr Opin Biotechnol 27: 8-14.

6. Aneta K. Urbanek, Waldemar Rymowicz, Aleksandra M. Mirończuk (2018) Degradation of plastics and plastic-degrading bacteria in cold marine habitats. Applied Microbiology and Biotechnology 102: 7669-78.

7. Toussaint B, Raffael B, Angers Loustau A, Gilliland D, Kestens V, et al. (2019) Review of micro- and nanoplastic contamination inthe food chain. Food Additives \& Contaminants: Part A 36: 639-73.

8. Bryant JA, Clemente TM, Viviani DA, Fong AA, Thomas KA, et al. (2016) Diversity and activity of communities inhabiting plastic debris in the North Pacific Gyre. mSystems 1: e00024-16.

9. Derraik JG (2002) The pollution of the marine environment by plastic debris: a review. Mar Pollut Bull 44: 842-52.

10. Andrady AL (2011) Microplastics in the marine environment. Mar Pollut Bull 62: 1596-605.

11. da Costa JP, Santos PSM, Duarte AC, Rocha Santos T (2016) (Nano)plastics in the environment - Sources, fates and effects. Sci Total Environ 15-26: 566-7. 
12. The University of Birmingham. How do organisms interact with microplastics that now pervade our rivers and oceans?

13. GESAMP (2016) Sources, fate and effects of microplastics in the marine environment: part two of a global assessment. In: Kershaw PJ, Rochmann CM (Eds.), Joint Group of Experts on the Scientific Aspects of Marine Environmental Protection. Rep Stud GESAMP No. 93: 220.

14. Sun J, Dai X, Wang Q, van Loosdrecht MCM, Bing Jie Ni (2019) Microplastics in wastewater treatment plants: Detection, occurrence and removal. Water Research 152: 21-37.

15. Kang J, Zhou L, Duan X, Sun H, Ao Z, et al. (2019) Degradation of Cosmetic Microplastics via Functionalized Carbon Nanosprings. Matter 1: 745-58.

16. Murty BS, Shankar P, Raj B, Rath BB, Murday J (2012) Unique Properties of Nanomaterials: 29-65.

17. Bratovcic A (2019) Different Applications of Nanomaterials and Their Impact on the Environment. SSRG International Journal of Material Science and Engineering 5: 1-7.

18. Maurer Jones MA, Gunsolus IL, Murphy CJ, Haynes CL (2013) Toxicity of Engineered Nanoparticles in the Environment. Anal Chem 85: 3036-49.

19. Ter Halle A, Jeanneau L, Martignac M, Jarde E, Pedrono B, et al. (2017) Nanoplastic in the North Atlantic Subtropical Gyre. Environ Sci Technol 51: $13689-97$. 20. Lambert S, Wagner M (2016) Characterisation of nanoplastics during the degradation of polystyrene. Chemosphere 145: 265-8.

21. Nasser F, Lynch I (2016) Secreted protein eco-coronamediates uptake and impacts of polystyrene nanoparticles on Daphnia magna. J Proteomics 137: 45-51.

22. von Moos N, Burkhardt Holm P, Köhle A (2012) Uptake and effects of microplastics on cells and tissue of the blue mussel Mytilus edulis L. after an experimental exposure. Environ Sci Technol 46: 11327-35.

23. Wright SL, Thompson RC, Galloway TS (2013) The physical impacts of microplastics on marine organisms: a review. Environ Pollut 178: 483-92.

24. Pedà C, Caccamo L, Fossi MC, Gai F, Andaloro F, et al. (2016) Intestinal alterations in European sea bass Dicentrarchus labrax (Linnaeus, 1758) exposed to microplastics: preliminary results. Environ Pollut 212: 251-6.

25. Avio CG, Gorbi S, Regoli F (2017) Plastics and microplastics in the oceans: from emerging pollutants to emerged threat. Mar Environ Res 128: 2-11.

26. Chae Y, An Y J (2017) Effects of micro and nanoplastics on aquatic ecosystems: current research trends and perspectives. Mar Pollut Bull 124: 624-32.

27. Foley CJ, Feiner ZS, Malinich TD, Höök TO (2018) A meta-analysis of the effects of exposure to microplastics on fish and aquatic invertebrates. Sci Total Environ 631-632: 550-9.

28. Barboza LGA, Gimenez BCG (2015) Microplastics in the marine environment: current trends and future perspectives. Mar Pollut Bull 97: 5-12.

29. Bouwmeester H, Hollman PCH, Peters RJB (2015) Potential health impact of environmentally released micro- and nanoplastics in the human food production chain: experiences from nanotoxicology. Environ Sci Technol 49: 8932-47.

30. van Cauwenberghe L, Janssen CR (2014) Microplastics in bivalves cultured for human consumption. Environ Pollut 193: 65-70.

31. Devriese LI, Van de Meulen MD, Maes T, Bekaert K, Paul Pont I, et al. (2015) Microplastic contamination in brown shrimp (Crangon crangon, Linnaeus 1758) from coastal waters of the southern north sea and channel area. Mar Pollut Bull 98: 179-87.

32. Vandermeersch G, Van Cauwenberghe L, Janssen CR, Marques A, Granby K, et al. (2015) A critical view on microplastic quantification in aquatic organisms. Environ Res 143: 46-53.

33. Romeo T, Pietro B, Pedà C, Consoli P, Andaloro F, et al. (2015) First evidence of presence of plastic debris in stomach of large pelagic fish in the Mediterranean Sea. Mar Pollut Bull 95: 358-61.

34. Collard F, Gilbert B, Compere P, Eppe G, Krishna D, et al. (2017) Microplastics in livers of European anchovies (Engraulis encrasicolus, L.). Environ Pollut 229: 1000-5.

35. Compa C, Ventero A, Iglesias M, Deudero S (2018) Ingestion of microplastics and natural fibres in Sardina pilchardus (Walbaum, 1792) and Engraulis encrasicolus (Linnaeus, 1758) along the Spanish Mediterranean coast. Mar Pollut Bull 128: 89-96.

36. Schymanski D, Goldbeck C, Humpf HU, Fürst P (2018) Analysis of microplastics in water by micro-Raman spectroscopy: release of plastic particles from different packaging into mineral water. Water Res 129: 154-62.

37. Kosuth M, Mason SA, Wattenberg EV (2018) Anthropogenic contamination of tap water, beer, and sea salt. PLoS One 13: e0194970.

38. Ragaert K, Delva L, Van Geem K (2017) Mechanical and chemical recycling of solid plastic waste. Waste Manag 69: 24-58.

39. Jia, X, Qin, C, Friedberger, T, Guan, Z, Huang, Z (2016) Efficient and selective degradation of polyethylenes into liquid fuels and waxes under mild conditions. Sci Adv 2: e1501591.

40. Garcia JM, Robertson ML (2017) The future of plastics recycling. Science 358: 870-2.

41. Aboulkas A, El harfi K, El Bouadili A (2010) Thermal degradation behaviors of polyethylene and polypropylene. Part I: Pyrolysis kinetics and mechanisms. Energy Conversion and Management 51: 1363-9.

42. Ekvall MT, Lundqvist M, Kelpsiene E, Šileikis E, Gunnarsson SB, et al. (2019) Nanoplastics formed during the mechanical breakdown of daily-use polystyrene products. Nanoscale Adv 1: 1055-61.

43. Romera Castillo C, Pinto M, Langer TM, Alvarez Salgado XA, Herndl GJ (2018) Dissolved organic carbon leaching from plastics stimulates microbial activity in the ocean. Nat Commun 9: 1430.

44. Pathak VM, Navnett (2017) Review on the current status of polymer degradation: a microbial approach. Bioresour Bioprocess 4: 15.

45. Singh P, Singh SM, Dhakephalkar (2014) Diversity, cold active enzymes and adaptation strategies of bacteria inhabiting glacier cryoconite holes of High Arctic. Extremophiles 18: 229-42.

46. Natalie P (2019) Researchers Have Created Tiny Springs To Tackle Marine Microplastic Pollution.Sustainable solutions and innovation.

47. Tofa TS, Kunjali KL, Paul S, Dutta J (2019) Visible light photocatalytic degradation of microplastic residues with zinc oxide nanorods. Environmental Chemistry Letters 17: 1341-6.

48. Shengying L, Shihong X, Lijun H, Fei X, Yonghong W, et al. (2010) Photocatalytic Degradation of Polyethylene Plastic with Polypyrrole/TiO ${ }_{2}$ Nanocomposite as Photocatalyst. Journal Polymer-Plastics Technology and Engineering 49: 400-6. 
49. Tian L, Chen Q, Jiang W, Wang L, Xie H, et al. (2019) A carbon-14 radiotracer-based study on the phototransformation of polystyrene nanoplastics in water versus in air. Environmental Science: Nano 6: 2907-17.

50. Ariza Tarazona MC, Villarreal Chiu JF, Barbieri V, Siligardi C, Cedillo González EI (2018) New strategy for microplastic degradation: green photocatalysis using a protein-based porous $\mathrm{NTiO}_{2}$ semiconductor. Ceramics International 45: 9618-24.

51. Water Source (2019) Could the Sun's radiation clean microplastics from wastewater and waterways? 